\title{
The distinct genetic pattern of ALS in Turkey and novel mutations
}

\author{
Aslıhan Özoğuza ${ }^{a}$ Özgün Uyan ${ }^{a}$, Güneş Birdal ${ }^{a}$, Ceren Iskender ${ }^{a}$, Ece Kartal ${ }^{a}$, \\ Suna Lahut ${ }^{a}$, Özgür Ömür ${ }^{\text {, }}$, Zeynep Sena Agim ${ }^{a}$, Aslı Gündoğdu Eken ${ }^{a}$, Nesli Ece Sen ${ }^{a}$, \\ Pınar Kavak ${ }^{b}$, Ceren Saygı a, Peter C. Sapp ${ }^{c}$, Pamela Keagle ${ }^{c}$, Yeşim Parman ${ }^{d}$, Ersin Tan e, \\ Filiz Koç ${ }^{\mathrm{f}}$, Feza Deymeer ${ }^{\mathrm{d}}$, Piraye Oflazer ${ }^{\mathrm{d}}$, Haşmet Hanağası ${ }^{\mathrm{d}}$, Hakan Gürvit ${ }^{\mathrm{d}}$, \\ Başar Bilgiç ${ }^{\mathrm{d}}$, Hacer Durmuş ${ }^{\mathrm{d}}$, Mustafa Ertaş ${ }^{\mathrm{g}}$, Dilcan Kotan ${ }^{\mathrm{h}}$, Mehmet Ali Akalın ${ }^{\mathrm{i}}$, \\ Halil Güllüoğlu ${ }^{j}$, Mehmet Zarifoğlu ${ }^{k}$, Fikret Aysal ${ }^{1}$, Nilgün Döşoğlu ${ }^{m}$, Kaya Bilguvar ${ }^{n}$, \\ Murat Günel $^{\mathrm{n}}$, Özlem Keskin ${ }^{\mathrm{o}}$, Tahsin Akgün ${ }^{\mathrm{P}}$, Hilmi Özçelik ${ }^{\mathrm{q}}$, John E. Landers ${ }^{\mathrm{c}}$, \\ Robert H. Brown ${ }^{c}$, A. Nazlı Başak ${ }^{a, *}$

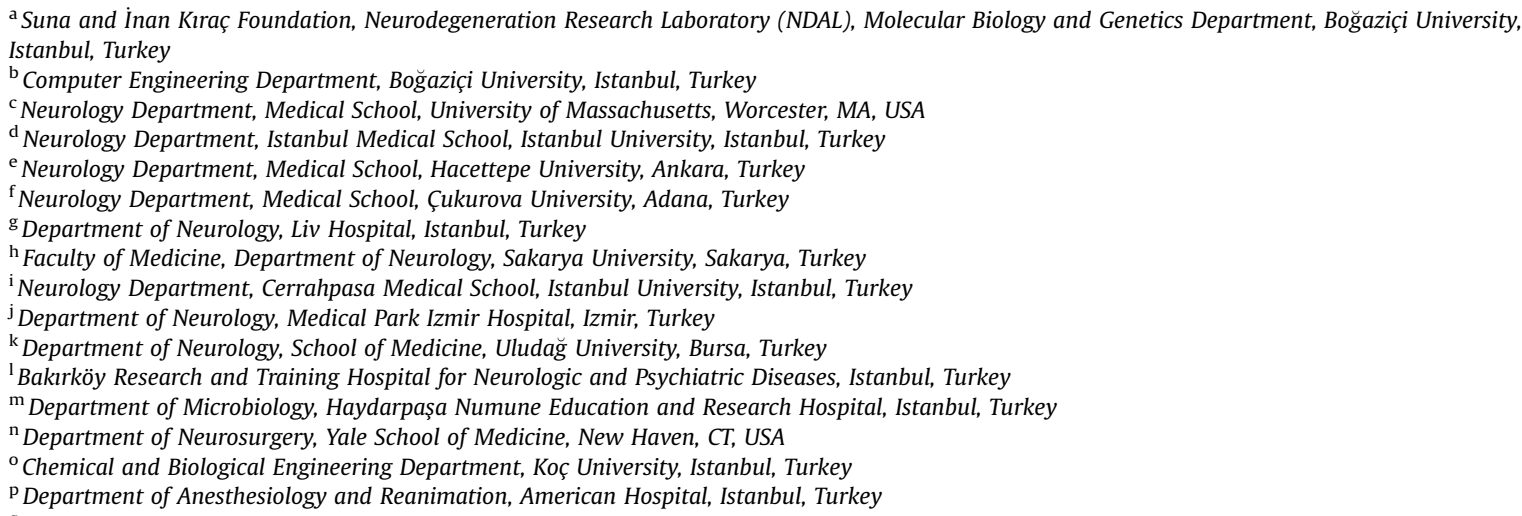

\section{A R T I C L E I N F O}

\section{Article history:}

Received 17 September 2013

Received in revised form 15 October 2014

Accepted 26 December 2014

Available online 10 January 2015

\section{Keywords:}

ALS

Turkey

SOD1

C9orf72

TDP-43

FUS

\begin{abstract}
A B S T R A C T
The frequency of amyotrophic lateral sclerosis (ALS) mutations has been extensively investigated in several populations; however, a systematic analysis in Turkish cases has not been reported so far. In this study, we screened 477 ALS patients for mutations, including 116 familial ALS patients from 82 families and 361 sporadic ALS (sALS) cases. Patients were genotyped for C9orf72 (18.3\%), SOD1 (12.2\%), FUS (5\%), TARDBP (3.7\%), and UBQLN2 (2.4\%) gene mutations, which together account for approximately $40 \%$ of familial ALS in Turkey. No SOD1 mutations were detected in sALS patients; however, C9orf72 (3.1\%) and UBQLN2 (0.6\%) explained 3.7\% of sALS in the population. Exome sequencing revealed mutations in OPTN, SPG11, DJ1, PLEKHG5, SYNE1, TRPM7, and SQSTM1 genes, many of them novel. The spectrum of mutations reflect both the distinct genetic background and the heterogeneous nature of the Turkish ALS population. (C) 2015 Elsevier Inc. All rights reserved.
\end{abstract}

\footnotetext{
* Corresponding author at: Suna and İnan Kıraç Foundation, Neurodegeneration Research Laboratory, Molecular Biology and Genetics Department, Boğaziçi University, Istanbul 34342, Turkey. Tel.: +90 212 3596679; fax: +90 2123597298 .

E-mail address: basak@boun.edu.tr (A.N. Başak).
}

\section{Introduction}

Amyotrophic lateral sclerosis (ALS) is an adult-onset neurodegenerative disorder characterized by the selective death of motor neurons in the motor cortex, brainstem, and spinal cord. ALS is rapidly progressive, leading to death in $2-5$ years after diagnosis. 
(Pasinelli and Brown, 2006). Today, the disease is mostly described as a multisystem disorder in which many different systems, including the nonmotor areas, are eventually affected (Ferraiuolo et al., 2011). ALS has a fairly uniform incidence throughout the world (2-3/100,000). Approximately, 5\%-10\% of ALS cases are familial ALS (fALS) and the rest sporadic ALS (sALS). fALS and sALS are almost indistinguishable in terms of clinical features. Because interestingly many fALS mutations have also recently been observed in SALS, genetic studies of fALS cases are expected to be informative in understanding the mechanisms, leading to sALS. Currently, the most common genes, which give rise to fALS when mutated, are the dynamic hexanucleotide expansion in chromosome 9 (C9orf72), superoxide dismutase 1 (SOD1), TARDNA-binding protein (TARDBP), fused in sarcoma (FUS), and ubiquilin 2 (UBQLN2) (Andersen and Al-Chalabi, 2011; Ticozzi et al., 2011). Mutations in all other fALS genes, like alsin (ALS2), senataxin (SETX), dynactin 1 (DCTN1), angiogenin (ANG), optineurin (OPTN), and spatacsin (SPG11), are relatively rare (Al-Chalabi et al., 2012).

Turkey is a large country with a high birth rate and consanguineous marriages (mostly between the first cousins) are rather the rule than the exception in the eastern parts of the country. Being at the crossroad of 2 continents and different civilizations, Turkey with its rich and ancient history is known to be ethnically very heterogeneous. In recent years, several population-based ALS studies have been conducted in different ethnic groups. To the best of our knowledge, this is the first report compiling the genetic basis of ALS in Turkey. In the framework of this study, we analyzed a cohort of 477 patients, using conventional methods and next generation technologies, to define the spectrum of ALS mutations in Turkey.

\section{Methods}

\subsection{Subjects}

This study includes a total of 477 Turkish ALS patients, who were referred to our center from the neurology departments of several hospitals throughout Turkey. El Escorial criteria were applied for clinical diagnosis (Brooks et al., 2000). From 477 patients, 443 (273 males and 170 females) were unrelated and thus included into the calculation of mutation frequencies. Out of 443,82 were familial (18\%) and $361(82 \%)$ isolated cases. In most isolated cases, we were able to trace the upper generations to be disease free. Two hundred Turkish control samples without any neurologic complaints were either anonymously collected from Haydarpaşa State Hospital Microbiology Department or chosen from healthy family members of the patients (96 males and 104 females). Informed consent was obtained from all the individuals. The Ethics Committee of Boğaziçi University approved this study. Additionally, all novel mutations identified in this study were further questioned in the Turkish exome database of The Scientific and Technological Research Council of Turkey (TÜBITAK).

\subsection{Mutation screening}

DNA was extracted from white blood cells using the MagNAPure Compact DNA Isolation System (Roche, Switzerland). Mutation screening was performed systematically in all fALS patients for C9orf72, SOD1, FUS, TARDBP, and UBQLN2 genes using polymerase chain reaction (PCR)-based Sanger sequencing (Macrogen, Korea; Refgen, Ankara and Iontek, Istanbul, Turkey), and only unrelated patients, 1 proband from each family, were included into mutation frequency calculations. All coding sequences of SOD1 and UBQLN2, including the flanking regions, exons 14 and 15 of FUS, and exon 5 of TARDBP were screened. The hexanucleotide repeat of C9orf72 was analyzed by repeat-primed-PCR and fragment length analysis (Renton et al., 2011).
sALS patients were so far screened for C9orf72, SOD1, and UBQLN2 mutations. Results were evaluated using the Chromas (Technelysium Pty Ltd, Australia) and Peak Scanner software (Life Technologies Corporation, Carlsbad, CA, USA). The sequences of primers used for the amplifications are available on request.

For SOD1-D90A haplotype analysis, 12 microsatellite markers were used, which are available on request. Haplotypes from 3 Turkish D90A patients and their unaffected family members were compared with the haplotypes of 21 Scandinavian D90A patients (samples kindly provided by Peter Andersen, Umea University, Sweden). A subset of these markers was also used to perform haplotype analysis for the Turkish and Chinese patients carrying the SOD1-A4S mutation (DNA samples of the Chinese patient kindly sent by Mitsuya Morita, Tochigi-ken, Honshu, Japan).

\subsection{Exome sequencing analyses}

All fALS patients, which could not be solved via conventional mutation screening methods, were subjected to whole-exome capture analysis at TUBITAK, Yale University, and University of Massachusetts Schools of Medicine. Paired-end sequencing was performed on Illumina HiSeq 2000 and 2500 DNA sequencing platforms. Alignment to the human reference genome (hg19) was accomplished using Burrows-Wheeler Aligner. Genome Analysis Toolkit was used for the quality control assessment and variant calling. Annotations of all variants were done by the ANNOVAR software. Filtering of the variants was performed using 1000 Genomes Project, NHLBI ESP, Exome Variant Server, and dbSNP versions. The presence and absence of all the variants, identified by whole-exome capture analysis, were confirmed by PCR and Sanger sequencing in patients and their affected and unaffected family members.

Potential impacts of novel mutations in this study were evaluated using functional online prediction programs, PolyPhen-2, PROVEAN, and SIFT; ClustalW2 estimated the conservation statuses of the mutation sites.

\section{Results}

\subsection{Clinical findings}

Four hundred and seventy-seven Turkish patients diagnosed with ALS participated in this study. Table 1 compiles the clinical

Table 1

Clinical features of the Turkish cohort

\begin{tabular}{llll}
\hline Clinical features & Total & fALS & sALS \\
\hline$\#$ M & 477 & 116 & 361 \\
F & 285 & 63 & 222 \\
M:F & 193 & 53 & 140 \\
SO & 1.5 & 1.2 & 1.6 \\
Limb & & & \\
Bulbar & 273 & 81 & 192 \\
Limb + bulbar & 79 & 11 & 68 \\
Unknown & 34 & 5 & 29 \\
AO & 89 & 17 & 72 \\
Mean \pm SD & & & $48.9 \pm 15$ \\
M \pm SD & $47.2 \pm 16$ & $41.9 \pm 18$ & $48.5 \pm 15$ \\
F \pm SD & $46.5 \pm 16$ & $40.1 \pm 18$ & $49.5 \pm 15$ \\
Juvenile $(<25)$ & $48.1 \pm 16$ & $44.2 \pm 18$ & 24 \\
Middle $(25-45)$ & 51 & 27 & 106 \\
Late $(>45)$ & 135 & 29 & 199 \\
Unknown & 251 & 52 & 91 \\
Range & 39 & 8 & $9-80$ \\
\hline
\end{tabular}

Key: ALS, Amyotrophic lateral sclerosis; AO, age of onset; F, female; fALS, familial ALS; M, male; SALS, sporadic ALS; SD, standard deviation; SO, site of onset; \#, numbers. 
Table 2

Genetic and clinical parameters of individuals with defined mutations

\begin{tabular}{|c|c|c|c|c|c|c|}
\hline Family & Sex & $\mathrm{AO}$ & so & Inheritance & Mutation & Predominating features \\
\hline \multicolumn{7}{|l|}{ fALS } \\
\hline C9ORF72\#1 & M & 32 & $\mathrm{~L}$ & $\mathrm{AD}$ & \multirow[t]{8}{*}{ Expansion $^{\mathrm{a}, \mathrm{b}}$} & Fast progression \\
\hline C9ORF72\#2 & $\mathrm{F}$ & 46 & NA & $\mathrm{AD}$ & & - \\
\hline C9ORF72\#3 & $\mathrm{M}$ & 46 & B & $\mathrm{AD}$ & & - \\
\hline C9ORF72\#4 & $\mathrm{M}$ & 56 & $\mathrm{~L}$ & $\mathrm{AD}$ & & - \\
\hline C9ORF72\#5 & $\mathrm{M}$ & 80 & $\mathrm{~L}$ & $\mathrm{AD}$ & & - \\
\hline C9ORF72\#6 & $\mathrm{M}$ & 63 & $\mathrm{~L}$ & $\mathrm{AD}$ & & - \\
\hline C9ORF72\#7 & $\mathrm{F}$ & 37 & $\mathrm{~L}$ & $\mathrm{AD}$ & & - \\
\hline C9ORF72\#8 & $\mathrm{F}$ & 62 & $\mathrm{~L}$ & $\mathrm{AD}$ & & - \\
\hline \multirow[t]{2}{*}{ C9ORF72\#9 } & $\mathrm{F}$ & 58 & $\mathrm{~L}$ & \multirow[t]{2}{*}{$\mathrm{AD}$} & \multirow[t]{2}{*}{ Expansion $^{\mathrm{a}, \mathrm{b}}$} & Dementia \\
\hline & $\mathrm{F}$ & 57 & - & & & Frontotemporal dementia \\
\hline \multirow[t]{3}{*}{ C9ORF72\#10 } & $\mathrm{M}$ & 58 & $\mathrm{~L}$ & \multirow[t]{3}{*}{$\mathrm{AD}$} & \multirow[t]{3}{*}{ Expansion $^{\mathrm{a}, \mathrm{b}}$} & - \\
\hline & M & 46 & B & & & Dementia \\
\hline & $\mathrm{F}$ & 53 & $\mathrm{~B}$ & & & - \\
\hline C9ORF72\#11 & $\mathrm{F}$ & 63 & B & $\mathrm{AD}$ & \multirow[t]{5}{*}{ Expansion $^{\mathrm{a}, \mathrm{b}}$} & - \\
\hline C9ORF72\#12 & $\mathrm{M}$ & 71 & $\mathrm{~L}$ & $\mathrm{AD}$ & & - \\
\hline C9ORF72\#13 & M & 54 & $\mathrm{~L}$ & $\mathrm{AD}$ & & Concurrent UBQLN2-S340I \\
\hline C9ORF72\#14 & $\mathrm{F}$ & 63 & $\mathrm{~L}$ & $\mathrm{AD}$ & & - \\
\hline C9ORF72\#15 & M & 62 & $\mathrm{~L}$ & $\mathrm{AD}$ & & ALS-parkinsonism-dementia complex \\
\hline \multirow[t]{2}{*}{ SOD1\#1 } & M & 19 & $\mathrm{~L}$ & \multirow[t]{2}{*}{$\mathrm{AD}$} & \multirow[t]{2}{*}{ H71Y* } & Very fast progression, ip \\
\hline & $\mathrm{F}$ & 57 & $\mathrm{~L}$ & & & Very fast progression, ip \\
\hline SOD1\#2 & M & 49 & $\mathrm{~L}$ & AR & $\mathrm{D} 90 \mathrm{~A}^{\mathrm{c}}$ & Stereotyped Scandinavian phenotype \\
\hline SOD1\#3 & $\mathrm{M}$ & 55 & $\mathrm{~L}$ & AR & $\mathrm{D} 90 \mathrm{~A}^{\mathrm{c}}$ & Stereotyped Scandinavian phenotype \\
\hline SOD1\#4 & $\mathrm{F}$ & 45 & $\mathrm{~L}$ & AR & $\mathrm{D}^{2} \mathrm{~A}^{\mathrm{c}}$ & Stereotyped Scandinavian phenotype \\
\hline \multirow[t]{2}{*}{ SOD1\#5 } & M & 20 & $\mathrm{~L}$ & \multirow[t]{2}{*}{$\mathrm{AD}$} & \multirow[t]{2}{*}{$\mathrm{A} 4 \mathrm{~S}^{\mathrm{d}}$} & Rapidly progressive atrophy \\
\hline & $\mathrm{F}$ & 44 & $\mathrm{~L}$ & & & Slow progression \\
\hline SOD1\#6 & M & 28 & $\mathrm{~L}$ & AR & N86S ${ }^{e}$ & Very fast progression \\
\hline SOD1\#7 & $\mathrm{F}$ & 52 & $\mathrm{~L}$ & $\mathrm{AD}$ & $\mathrm{L}_{144 \mathrm{~F}^{\mathrm{f}}}$ & Classical ALS \\
\hline SOD1\#8 & $\mathrm{M}$ & 59 & $\mathrm{~L}$ & $\mathrm{AD}$ & $\mathrm{L} 144 \mathrm{~F}^{\mathrm{f}}$ & Classical ALS \\
\hline SOD1\#9 & $\mathrm{F}$ & 54 & $\mathrm{~L}$ & $\mathrm{AD}$ & $\mathrm{L} 144 \mathrm{~F}^{\mathrm{f}}$ & Classical ALS \\
\hline SOD1\#10 & $\mathrm{F}$ & 46 & $\mathrm{~L}$ & $\mathrm{AD}$ & $\mathrm{V} 149 \mathrm{G}^{\mathrm{f}}$ & Classical ALS \\
\hline FUS\#1 & M & 16 & $\mathrm{~L}$ & $\mathrm{AD}$ & $\Delta 144-149 a^{g}$ & ip \\
\hline FUS\#2 & $\mathrm{F}$ & 32 & $\mathrm{~L}$ & $\mathrm{AD}$ & R524M* & ip \\
\hline FUS\#3 & $\mathrm{M}$ & 53 & $\mathrm{~L}$ & $\mathrm{AD}$ & R524M* & Fast progression \\
\hline FUS\#4 & M & 14 & $\mathrm{~L}$ & $\mathrm{AD}$ & $\mathrm{P} 525 \mathrm{~L}^{\mathrm{h}}$ & De novo, fast progression \\
\hline \multirow[t]{2}{*}{ TDP-43\#1 } & M & 58 & $\mathrm{~L}$ & \multirow[t]{2}{*}{$\mathrm{AD}$} & \multirow[t]{2}{*}{$\mathrm{A} 315 \mathrm{~T}^{\mathrm{i}}$} & - \\
\hline & $\mathrm{F}$ & 58 & $\mathrm{~L}$ & & & Man in barrel syndrome \\
\hline TDP-43\#2 & $\mathrm{F}$ & 57 & $\mathrm{~L}$ & $\mathrm{AD}$ & $\mathrm{A} 315 \mathrm{~T}^{\mathrm{i}}$ & - \\
\hline TDP-43\#3 & $\mathrm{F}$ & 42 & $\mathrm{~L}+\mathrm{B}$ & $\mathrm{AD}$ & $\mathrm{I} 383 \mathrm{~V}^{\mathrm{j}}$ & - \\
\hline & M & 67 & $\mathrm{~L}+\mathrm{B}$ & & & Fast progression \\
\hline UBQLN2\#1 & M & 26 & $\mathrm{~L}$ & $\mathrm{X}$ linked & P506S ${ }^{\mathrm{k}}$ & - \\
\hline UBQLN2\#2 & M & 22 & $\mathrm{~L}$ & $\mathrm{X}$ linked & $\mathrm{P}^{2} 25 \mathrm{~S}^{1}$ & ip \\
\hline OPTN\# 1 & M & 42 & $\mathrm{~L}$ & AR & $\Delta$ AA del at P.359* & - \\
\hline & $\mathrm{M}$ & 48 & $\mathrm{~L}$ & & & - \\
\hline & $\mathrm{M}$ & NA & $\mathrm{L}$ & & & - \\
\hline & $\mathrm{F}$ & 43 & B & & & - \\
\hline OPTN\#2 & $\mathrm{F}$ & 30 & NA & AR & $\Delta$ AA del at P.359* & - \\
\hline OPTN\#3 & M & 33 & B & AR & M98K/G291fs* & - \\
\hline & M & 36 & $\mathrm{~L}$ & & & - \\
\hline SPG11\#1 & M & 23 & $\mathrm{~L}$ & AR & N1962S*/Y2272X* & - \\
\hline SPG11\#2 & $\mathrm{F}$ & 14 & L & AR & F2265L* & - \\
\hline & M & 16 & $\mathrm{~L}$ & & & - \\
\hline DJ1\#1 & $\mathrm{M}$ & 24 & $\mathrm{~L}$ & AR & Q45X* & ALS-parkinsonism-dementia complex \\
\hline & $\mathrm{F}$ & NA & NA & & & \\
\hline
\end{tabular}


Table 2 (continued)

\begin{tabular}{|c|c|c|c|c|c|c|}
\hline Family & Sex & $\mathrm{AO}$ & SO & Inheritance & Mutation & Predominating features \\
\hline PLEKHG5\#1 & $\mathrm{M}$ & 13 & $\mathrm{~L}$ & AR & $\mathrm{P} 630 \mathrm{H}^{*}$ & Lower motor neuron dominance \\
\hline SYNE\#1 & $\begin{array}{l}M \\
M\end{array}$ & $\begin{array}{l}20 \\
21\end{array}$ & $\begin{array}{l}\mathrm{L} \\
\mathrm{L}\end{array}$ & AR & Q7644X* & $\begin{array}{l}\text { Spastic ataxic gait, dysarthria, dysmetria, } \\
\text { fast progression }\end{array}$ \\
\hline SYNE\#2 & $\begin{array}{l}\mathrm{F} \\
\mathrm{F} \\
\mathrm{F}\end{array}$ & $\begin{array}{l}26 \\
17 \\
30\end{array}$ & $\begin{array}{l}\mathrm{L} \\
\mathrm{L} \\
\mathrm{L}\end{array}$ & AR & R7842X* & $\begin{array}{l}\text { Spastic ataxic gait, dysarthria, dysmetria, } \\
\text { oculomotor abnormality }\end{array}$ \\
\hline TRPM7/SQSTM1\#1 & $\begin{array}{l}\mathrm{M} \\
\mathrm{M}\end{array}$ & $\begin{array}{l}17 \\
19\end{array}$ & $\begin{array}{l}\mathrm{L} \\
\mathrm{L}\end{array}$ & $\mathrm{AD}$ & $\mathrm{T} 1482 \mathrm{I}^{\mathrm{m}} / \mathrm{E} 274 \mathrm{D}^{\mathrm{n}}$ & - \\
\hline sALS & & & & & & \\
\hline C9ORF72 & $\begin{array}{l}\mathrm{F} \\
\mathrm{M} \\
\mathrm{M} \\
\mathrm{F} \\
\mathrm{F} \\
\mathrm{M} \\
\mathrm{F} \\
\mathrm{M} \\
\mathrm{M} \\
\mathrm{M} \\
\mathrm{M}\end{array}$ & $\begin{array}{l}69 \\
48 \\
49 \\
48 \\
55 \\
42 \\
52 \\
53 \\
56 \\
69 \\
60\end{array}$ & $\begin{array}{l}\mathrm{L} \\
\mathrm{NA} \\
\mathrm{NA} \\
\mathrm{L}+\mathrm{B} \\
\mathrm{L} \\
\mathrm{L} \\
\mathrm{L} \\
\mathrm{L} \\
\mathrm{L}+\mathrm{B} \\
\mathrm{B} \\
\mathrm{L}\end{array}$ & Sporadic & Expansion $^{\mathrm{a}, \mathrm{b}}$ & $\begin{array}{l}\text { Dementia, fast progression } \\
- \\
- \\
- \\
- \\
- \\
- \\
- \\
- \\
\text { Dementia } \\
-\end{array}$ \\
\hline UBQLN2 & $\begin{array}{l}M \\
F\end{array}$ & $\begin{array}{l}14 \\
16\end{array}$ & $\begin{array}{l}\mathrm{L} \\
\mathrm{L}\end{array}$ & Sporadic & $\begin{array}{l}\text { M392I* } \\
\text { M392I* }\end{array}$ & $\begin{array}{l}\text { Drop foot } \\
\text { Madras-type MND }\end{array}$ \\
\hline
\end{tabular}

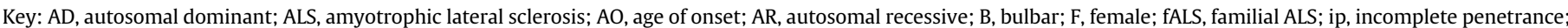
L, limb; M, male; MND, motor neuron disease; N, normal; NA, not available; sALS, sporadic ALS; SO, site of onset; *, Novel.

a Dejesus-Hernandez et al. (2011).

b Renton et al. (2011).

c Andersen et al. (1995).

d Hayward et al. (1998).

e Nakanishi et al. (1998)

f Deng et al. (1993).

g Belzil et al. (2011).

h Chio et al. (2009).

i Gitcho et al. (2008).

j Rutherford et al. (2008).

k Vengoechea et al. (2013).

1 Deng et al. (2011).

m Hermosura et al. (2005).

n rs55793208.

features of the Turkish patient cohort consisting of 443 probands and 34 affected family members.

\subsection{Genetic findings}

The genetic and clinical findings of 116 fALS and 361 sALS patients with defined mutations are compiled in Table 2, and the origins of the patients are indicated in Fig. 1. Pedigrees with corresponding numbers are provided in Figs. 2 and 3 and Supplementary Figs. 1-4. We report C9orf72, SOD1, FUS, TARDBP, and UBQLN2 mutation frequencies as $18.3 \%, 12.2 \%, 5 \%, 3.7 \%$, and $2.4 \%$ in fALS cases, respectively. Exome sequencing revealed mutations in OPTN, SPG11, DJ1, PLEKHG5, SYNE1, SQSTM1, and TRPM7 in several pedigrees. In 361 sALS patients, no SOD1 lesions were present; however, mutations in C9orf72 (3.1\%) and UBQLN2 (0.6\%) were found.

\subsubsection{C9orf72}

The dominant hexanucleotide repeat expansion on chromosome 9 (C9orf72) was heterozygously present in 18 fALS patients and 11 apparently sALS cases (Table 2). In a few families with this mutation, disease progression was fast. Three out of 4 C9orf72 expansion carriers in our cohort exhibited frontotemporal dementia-type dementia in addition to motor neuron symptoms, and 1 had only dementia. Intrafamilial phenotypic heterogeneity was observed in several pedigrees, and 1 patient had ALS-parkinsonism-dementia complex (families C9orf72\#1, C9orf72\#2, and C9orf72\#3) (Fig. 2).

\subsubsection{SOD1}

Sequencing the coding regions of the SOD1 gene revealed 6 different mutations (H71Y, D90A, A4S, N86S, L144F, and V149G) in 11 fALS patients; D90A and L144F were present in 3 families (Table 2). None of the sALS cases was found to carry SOD1 mutation.

The H71Y mutation (family SOD1\#1), not reported before, was identified in heterozygous form in a young fALS patient with a very fast disease progression of 1 year (Table 2, Fig. 2). The father, currently 50-year old, carries the same mutation without manifesting the disease, whereas a paternal aunt, also gene positive, has succumbed to ALS at the age of 57 years within 8 months. This variant was not present in ALSoD, dbSNP, 1000 Genomes, Exome Server Database, and in 200 Turkish controls, whom we screened for H71Y. The mutation was also not present in approximately 600 individual in the TÜBITAK exome database. All 3, PolyPhen-2, SIFT, and PROVEAN, tools indicate this change in a highly conserved position of SOD1 as deleterious.

SOD1-D90A was shown to behave as a recessive trait in 3 Turkish families (SOD1\#2, SOD1\#3, and SOD1\#4), whose clinical phenotypes displayed the stereotyped lower limb onset with mild 


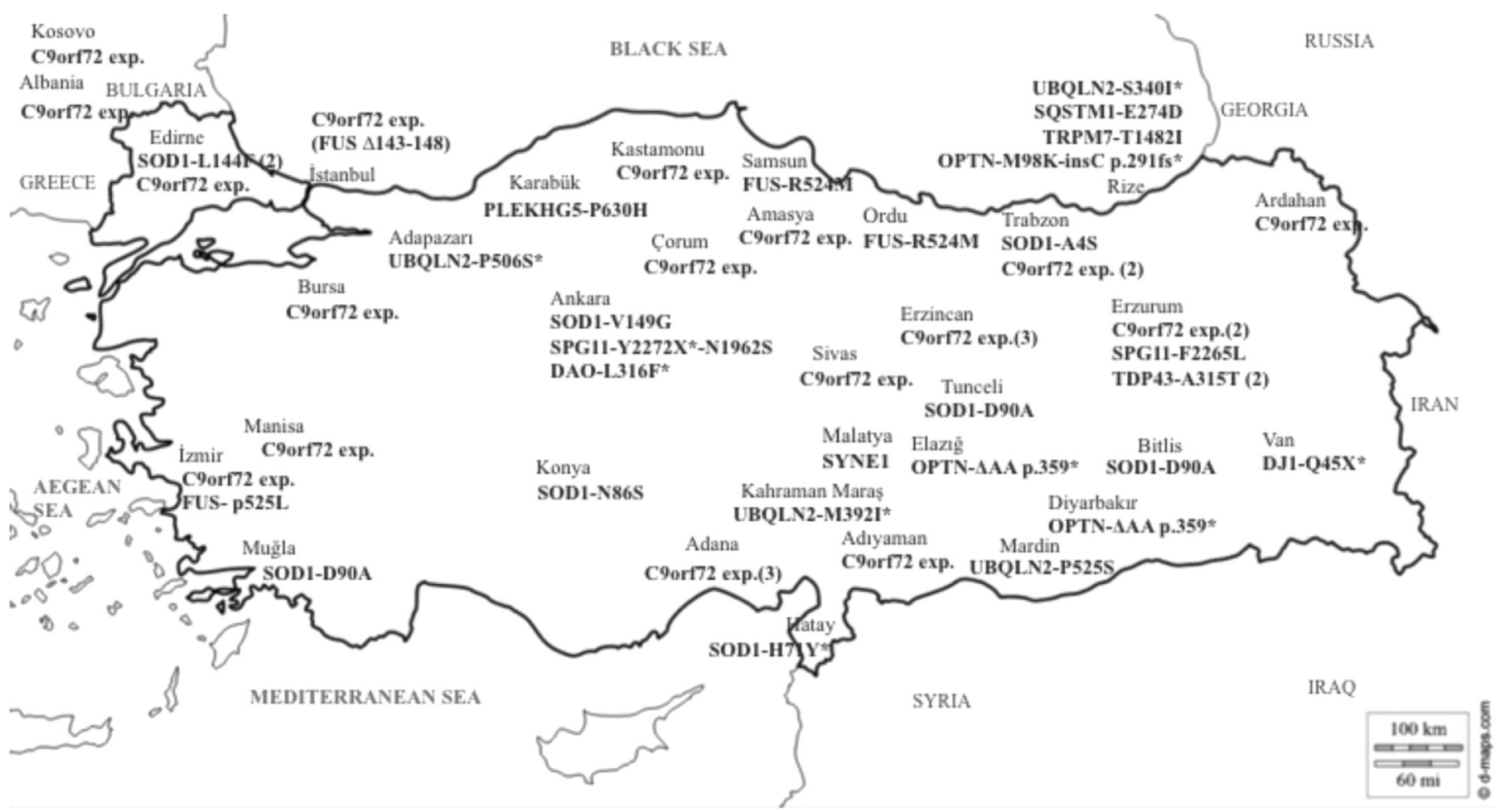

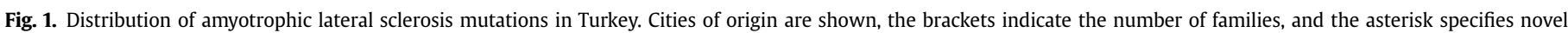
mutations.

and prolonged disease (Andersen et al., 1995, Table 2, Supplementary Fig. 1). Evidence for a common ancestry between these 3 families and the Scandinavian patients was confirmed by the haplotype analysis.

The rare SOD1-A4S mutation is defined in this study in a large family (SOD1\#5) from the northern coast of Turkey. ALS is dominantly segregating in 4 affected members of the family with intrafamilial heterogeneity in disease onset and progression (Table 2, Supplementary Fig. 2). The A4S mutation has only been reported once in the literature in a Chinese patient whose phenotype was not described (Nakanishi et al., 1998). Haplotype analysis of both the Turkish and Chinese patients did not reveal a clear overlap for a common ancestry; using more markers would clarify whether both patients have common origins.

In family SOD1\#6, the homozygous N86S mutation was present in one of the offspring of a consanguineous couple. The early-onset and the fast disease progression in the patient are also in agreement with a previous report (Hayward et al., 1998). L144F and V149G mutations were found in the index cases of families SOD1\#7, SOD1\#8, SOD1\#9, and SOD1\#10 (Table 2, Supplementary Fig. 2).

\subsubsection{FUS and TARDBP}

Sequencing of exons 14 and 15 of the FUS gene revealed 2 known and the novel R524M mutations in 4 patients. The heterozygous deletion of 18 nucleotides in the well-conserved QGSY-rich region of FUS ( $\Delta$ G144-Y149) was identified in a juvenile male patient (FUS\#1). The mother (51 years) and the maternal grandfather $(>80$ years) of the proband, carrying the same deletion, were asymptomatic at the time of diagnosis. Incomplete penetrance was also observed in families FUS\#2 and FUS\#3 with multiple affected sibs with the novel R524M mutation. DNA analysis of the asymptomatic parents in FUS\#2 is in process (Table 2, Supplementary Fig. 3). The P525L mutation in the deceased juvenile male patient of family
FUS\#4, which is absent in both parents investigated, seems to be a de novo mutation (Table 2, Fig. 2).

The TDP43-A315T mutation was identified in 2 unrelated families (TDP-43\#1 and TDP-43\#2). The affected sibs in family TDP43\#1 presented with distinct ALS phenotypes. The I383V mutation identified in family TDP-43\#3 resulted in different disease manifestations in the father and his daughter regarding onset and progression (Table 2, Supplementary Fig. 3).

\subsubsection{UBOLN2}

All 477 individuals with ALS and 200 neurologically healthy control subjects were screened for the entire coding sequence of the UBQLN2 gene. This revealed 3 distinct nonsynonymous variations: P506S (novel), P525S in 2 fALS, and M392I (novel) in 2 sALS cases (Table 2, Fig. 3).

The S340I change was identified in 3 unrelated families. The proband of family UBQLN2\#3 (age of onset, 12 years), offspring of a first cousin marriage, has a slow progressive disease and inborn mental retardation. The bedridden grandfather ( $>80$ years), also gene positive, manifests a similar slow progressive motor neuron type of disease with slight mental retardation, whereas the mother (48 years) and the older brother (30 years) of the proband, both carriers of S340I, are asymptomatic. In family UBQLN2\#4, dementia in the index case is very dominant. In this generation, there are 3 female patients deceased with ALS and an older sister of the proband with manifested disease for 6 years. Her older brother, S340I positive, is currently asymptomatic. Another family (UBQLN2\#5) consists of a proband with the S340I mutation and his yet asymptomatic mother, who is gene positive (Fig. 3).

Among 361 sALS cases investigated, a novel M392I variation was detected in 2 unrelated juvenile patients (Table 2). 1000 Genomes, dbSNP, and Exome Server databases do not contain this variation, which was also absent in 200 Turkish control samples. The 
C9ORF72\#1

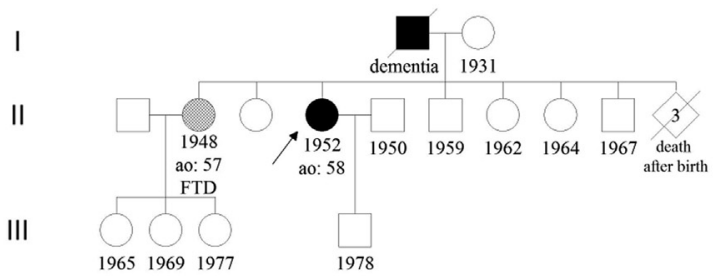

C9ORF72\#3

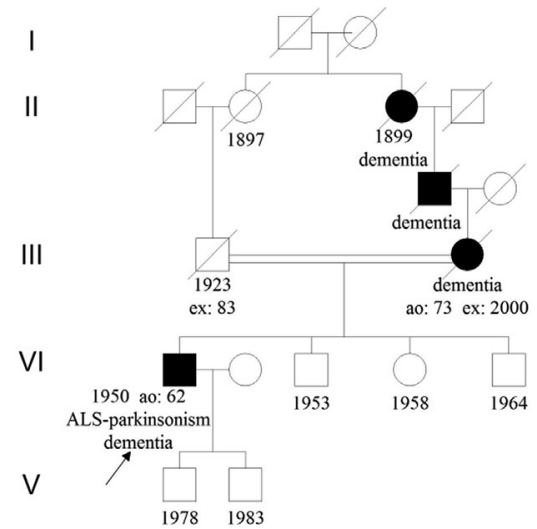

C9ORF72\#2

II

III

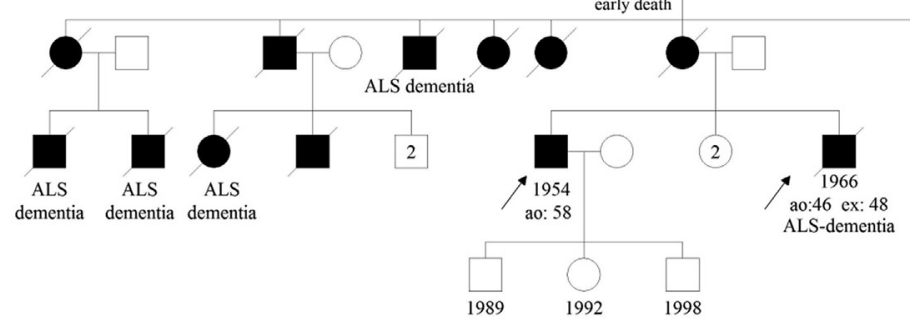

IV
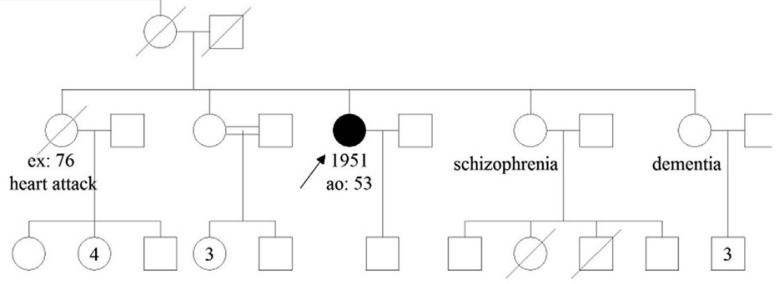

SOD1\#1-H71Y

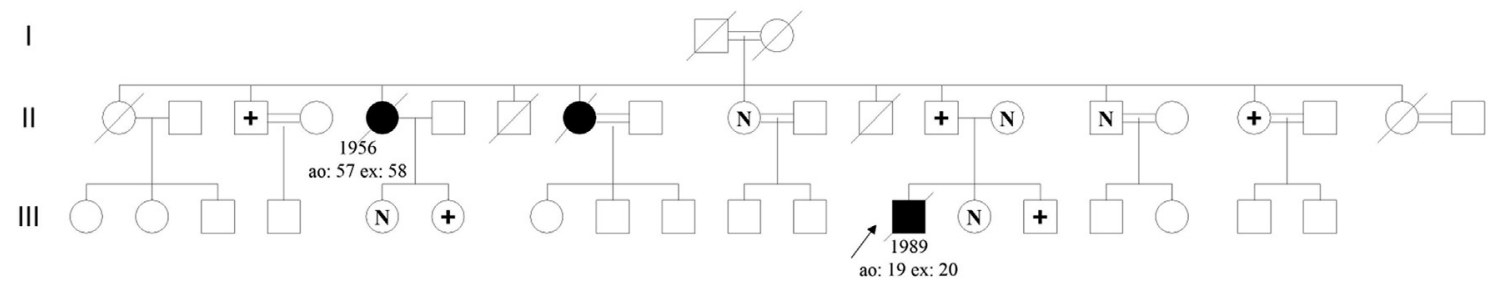

FUS\#4-P525L

I

II

III
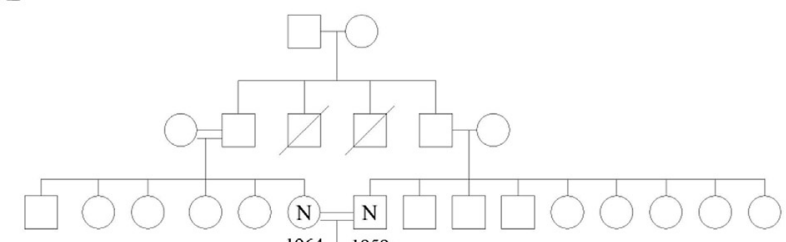

$\mathbf{N}$ normal $\bigcirc$ sex unknown

frontotemporal dementia

IV

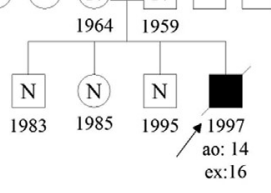

+ mutation positive/ no disease manifestation

Fig. 2. Five Turkish pedigrees with different ALS mutations

mutation was also not present in approximately 600 individual in the TÜBITAK exome database.

\subsubsection{Genes identified by exome sequencing analyses}

Out of 116 fALS patients investigated by conventional PCR-based techniques, $40 \%$ of our cohort was solved. The remaining ALS cases were subjected to whole-exome sequencing, which revealed several rarely mutated genes, so far in 10 distinct families.
The novel AA deletion in the OPTN gene identified in 2 consanguineous families, OPTN\#1 and OPTN\#2, leads to a frameshift at codon 359, resulting in a truncated protein. In the 4 affected members of the OPTN\#1 family, there is an apparent intrafamilial clinical heterogeneity, patient IV.3 presenting with cognitive impairment at her late 30s. In the second family (OPTN\#2), there are 3 affected sibs all of whom succumbed to ALS within 2-8 years (Table 2, Supplementary Fig. 4). 
UBQLN2\#1-P506S

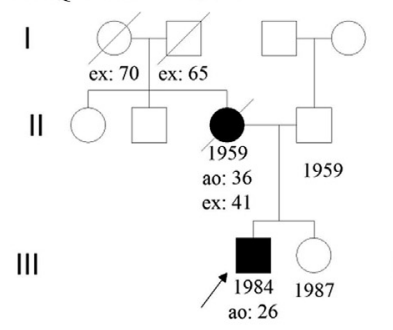

UBQLN2\#4-S340I

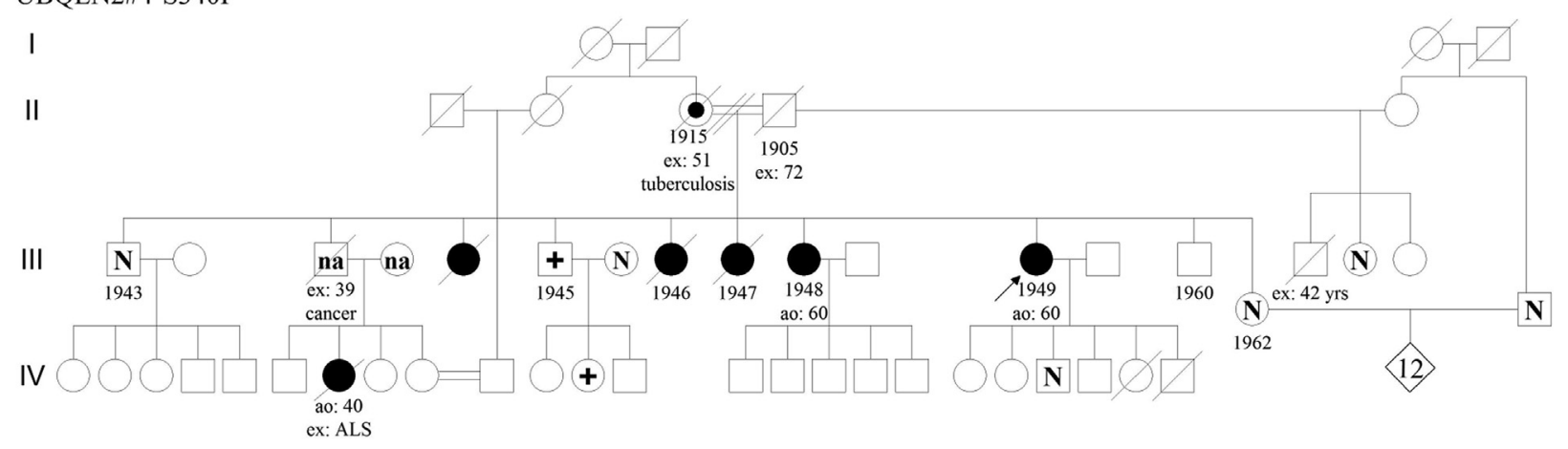

UBQLN2\#2-P525S

I

II

III

IV

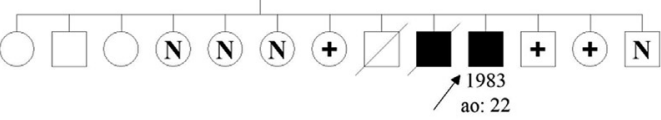

UBQLN2\#3-S340I

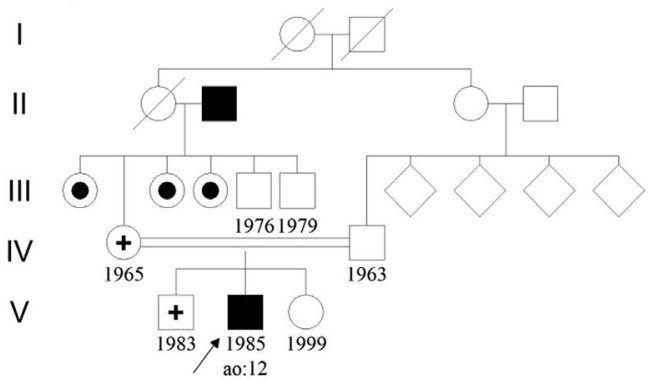

UBQLN2\#5-S340I
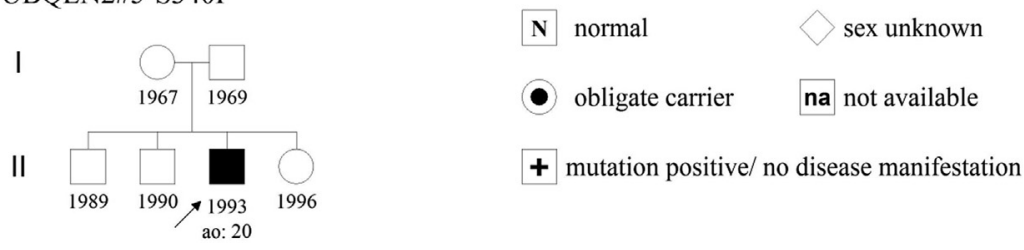

Fig. 3. Turkish pedigrees with UBQLN2 mutations

In a family, where 2 young sibs from consanguineous parents had a complicated differential diagnosis, exome sequencing revealed the presence of a homozygous mutation, F2265L, in SPG11. Both patients now in their 30s have slow progression and long disease duration in accordance with the previous reports (Daoud et al., 2012; Orlacchio et al., 2010) (Table 2, Supplementary Fig. 4).

In a consanguineous family with 10 children, 3 were reported with clinical features of motor neuron disease in addition to predominating parkinsonism and dementia. Exome sequencing revealed a novel homozygous nonsense mutation in the DJ1 gene (Q45X), previously reported as cause of Parkinson's disease and ALS-parkinsonism-dementia complex (Annesi et al., 2005). The mutation was validated by Sanger sequencing in the family members available (Table 2, Supplementary Fig. 4).

Another novel homozygous variation $(\mathrm{P} 630 \mathrm{H})$ was identified in the PLEKHG5 gene of a very young male patient (age of onset, 13 years) from consanguineous parents. The child presented with a lower motor neuron type of disease with slow progression, phenotypically resembling the family described in the large pedigree from Mali (Maystadt et al., 2007) (Table 2, Supplementary Fig. 4). We have also identified novel mutations (Q7644X and $\mathrm{R} 7842 \mathrm{X}$ ) in the SYNE1 gene (previously related to pure ataxia) in 2 independent families harboring several individuals diagnosed with motor neuron disease accompanied by ataxia (Table 2 ).

In 3 of our families, complex inheritance is suspected. In the first family, the proband has inherited 2 different SPG11 mutations (N1962S and Y2272X) in homozygous state. In the second family, 2 OPTN mutations (M98K and G291fs) were found in 2 sibs again in homozygous state. In both families, parents are first cousins. SPG11Y2272X and OPTN-G291fs mutations are novel. Additionally, there is a third family in our cohort in which 2 juvenile ALS patients (sibs) have dominant mutations in 2 distinct genes, TRPM7 (T1482I) and SQSTM1 (E274D), previously reported as rare causes of ALSparkinsonism-dementia complex and ALS, respectively (Fecto et al., 2011; Hermosura et al., 2005). The parents and the sister of the probands were unaffected at the time of diagnosis and are unfortunately not available to us for further analysis (Table 2, Supplementary Fig. 4).

\section{Discussion}

Turkey, with its wealthy historical background and unique geography at the southeastern border of Europe, forms a natural bridge between Europe and Asia. The large coastal areas at the Mediterranean Sea and extensive rural parts bordering the Near Eastern countries and the Black Sea make Turkey a rich genetic pool with a high ethnic heterogeneity. In contrast with other European populations, in which family sizes have been decreasing steadily in the last 50 years, Turkey is still very dynamic, with high birth rates (17/1000 vs. $7-10 / 1000$ in Europe) and traditionally large kindreds containing several living generations and an impressive number of offspring (www.cia.gov). Because close consanguineous marriages are still part of the Turkish culture, exceeding $60 \%$ in the eastern parts of the country, the number of autosomal recessively inherited forms of diseases is in excess of what is to be expected. Turkey's population of 75 million is very young, $50 \%$ being younger than 30 years. The 40- to 74-year age bracket applies approximately to only $30 \%$ of the 
population. Lowered life expectancy and an earlier age at death from other diseases may also limit the size of the older more susceptible population. Moreover, because adequately designed epidemiological studies and a systematic medical registry throughout the country are not available, these factors altogether complicate complete case ascertainment; thus, we can only make rough estimations about the prevalence of ALS in Turkey, which is 6000-7000.

In this study, we have carried out a comprehensive nationwide genetic analysis of ALS. Because we are the major reference center in Turkey involved in systematic clinical investigation of basic and genetic research on ALS, we believe to have recruited the largest patient material; thus, the results described here are not only the first but also a realistic reflection of the distribution of ALS mutations in Turkey.

Our cohort consists of a total of 477 Turkish patients, 82 fALS families (including 116 patients), and 361 sALS cases. The rate of fALS across population-based studies is around $5 \%-10 \%$, with a gradient falling from north to south of Europe (Novembre et al., 2008). Our patient population reflects a much higher rate of $17 \%$. A plausible explanation for this high ratio in favor of fALS is the high consanguinity in our cohort, harboring 28 recessive inheritance patterns in 82 pedigrees. In addition, some of the recessive fALS patients may have been classified as sporadic, if there was no disease in another family member. On the other hand, sALS seems to have a significant genetic component of its own, making the picture between fALS and sALS blurred. Molecular findings have shown that the distinction between fALS and sALS is to a great extent artificial; several fALS-causing genes have been found mutated in apparently sALS, which may be because of low penetrance (Hanby et al., 2011). The most prominent example is the C9orf72 expansion displaying a relatively frequent cause of sALS.

The C9orf72 mutation shows variable frequencies in fALS cases worldwide with the highest numbers (46\%) in Finland, compared with $18.3 \%$ in our Turkish fALS cohort. In sporadic cases, the frequencies are reported around $5 \%$ in Caucasian populations, again with the highest numbers in the Finnish population (21.1\%); 3.1\% was observed in our sALS population (Majounie et al., 2012). The AOs in our cohort were variable ranging from 32 to 80 years with a tendency to older onset, in accordance with the literature (Millecamps et al., 2012). Because C9orf72 considerably contributes to ALS and dementia in Turkey, it should be included in the screening strategy of Turkish ALS and also dementia patients.

The frequencies of SOD1 mutations in fALS have been reliably investigated in the Caucasian populations of North America and Europe (Andersen and Al-Chalabi, 2011; Pfister et al., 2013). Among the known SOD1 mutations, a geographical distribution begins to emerge, as more ethnic groups are being screened. Interestingly, there seems to be a north-south gradient decreasing across Europe with higher numbers in Sweden (35\%) and Finland (42.9\%) and lower rates in Mediterranean countries $(\sim 15 \%)$ (Battistini et al., 2005; Gamez et al., 2006; Rabe et al., 2010). The $12.2 \%$ frequency of SOD1 in Turkish fALS families is consistent with other Mediterranean countries.

Among the SOD1 mutations identified in this study, the heterozygous $\mathrm{H} 71 \mathrm{Y}$ mutation changes a positively charged histidine to a neutral tyrosine, which may affect the conformation of SOD1. The conserved location and the findings of prediction tools support the deleterious nature of this variant, strongly contributing to the ALS phenotype in the proband and in the affected paternal aunt. The fact that the father and several close relatives in the family have not developed ALS, although gene positive, points to a variable penetrance rate of $\mathrm{H71Y}$, which may be because of modifying genes (Fig. 2), to be unraveled via ongoing exome analysis.

Being unique among human genetic disorders, the D90A mutation has been identified both in recessive and dominant pedigrees. Independent of their geographical location, D90A recessive pedigrees share the same ancient founder haplotype. This applies also to all 3 D90A-ALS families in this study. The incomplete penetrance of homozygous D90A in family SOD1\#4 is a very rare but a previously observed finding (P. Andersen, personal communication) (Supplementary Fig. 1).

TARDBP and FUS genes, with structural and functional similarities, were shown to be responsible for a considerable proportion of fALS and also sALS cases, suggesting for the first time mechanisms implicated in RNA biology in the development of ALS (Lattante et al., 2013). In our cohort, the mutation frequencies of TARDBP and FUS were $2.4 \%$ and $3.7 \%$, respectively. The presence of the de novo mutation, FUS-P525L, in a Turkish family is a common finding (Calvo et al., 2014).

Mutations in the X-linked UBQLN2 gene were first described in 5 ALS families in the Caucasian American population (2.0\%) (Deng et al., 2011). Successive studies identified several fALS-linked UBQLN2 mutations with similar frequencies, whereas no mutations were shown in Dutch (Gellera et al., 2013; Millecamps et al., 2012; van Doormaal et al., 2012; Williams et al., 2012). Among the UBQLN2 mutations in our cohort, the P525S mutation was identified in 5 members of an extended family (UBQLN2\#2) with close consanguinity. With 2 affected individuals in the family and several gene-positive family members, who are asymptomatic so far, an incomplete penetrance is expected, which may be explained by unequal $\mathrm{X}$ inactivation in the females, for example, the mother. Interestingly, the youngest brother was reported to have a different neurologic impairment with the features of Friedreich ataxia, which was excluded. Clinical follow-up of the family is important (Fig. 3).

The S340I variation in the UBQLN2 gene, so far only reported in a healthy individual without a neurodegenerative disease, was found in our cohort in 3 ALS families with several affected individuals (Dillen et al., 2013). However, in all families, the segregation of the disease with S340I was ambiguous because several gene-positive individuals are free of disease. The variation was found in 1 out of 200 Turkish controls and in an ALS patient with the C9orf72 mutation in our cohort. Additionally, S340I was also present in 1 Turkish patient with autosomal recessive spastic ataxia of Charlevoix-Saguenay (ARSACS) and in a Turkish schizophrenia patient and his unaffected mother (not included in the ALS cohort under study). This mutation is reported for the first time in this study in 3 independent families with several affected individuals as a possible cause of ALS. On the other hand, the presence of several unaffected but gene-positive individuals in these families renders the pathogenicity of this rarely reported variation, outside of the PXX domain, questionable.

The presence of the novel M392I mutation in 2 young ALS patients with no family history, but in none of the controls, supports the pathogenic nature of the mutation, located in a highly conserved region of the $U B Q L N 2$ gene. One of the patients had the clinical characteristics of the Madras pattern of motor neuron impairment with the only distinction of a fairly rapid progression. Functional and further genetic analyses are expected to enlighten the mechanisms and pathogenicity underlying UBQLN2-based disease.

Exome analyses of 10 families revealed several novel and known mutations in ALS-associated genes. Four of these, DJ1, SYNE1, SPG11, and PLEKHG5, do not give rise to classical ALS but rather to an earlyonset lower motor neuron type of disease with slow progression. Mutations in the PLEKHG5 gene have been reported as rare causes of autosomal recessive lower motor neuron disease with childhood onset and distal hereditary motor neuropathy. The homozygous $\mathrm{P} 630 \mathrm{H}$ missense mutation in a highly conserved position of the protein, preceding the $\mathrm{PH}$ domain, similar to the P647S mutation reported earlier, gives rise to a lower motor neuron disease with slow progression in the juvenile patient (Maystadt et al., 2007). The $\mathrm{PH}$ domain, involved in motor neuron maintenance and protection, is also implicated in the ALS2 gene, a causative gene for juvenile 
ALS, primary lateral sclerosis, and infantile-onset ascending spastic paraplegia (Hadano et al., 2001).

The recent wealth of genes giving rise to ALS and the increasing locus heterogeneity show us once more the complex nature of ALS. A recent and exciting finding, which carries ALS research to a new level of complexity, indicates that also fALS may have a complex and even oligogenic inheritance pattern, in which not only 1 gene but also several genes may be implicated. The 2 recessive families, one with 2 OPTN and the other with 2 SPG11 mutations, in addition to the dominant TRPM7/SQSTM1 family identified in this study, confirm the hypothesis. This wealth of genes is expected to allow us to pinpoint the precise genetics and the molecular mechanisms behind the disease, offering new opportunities for therapeutic intervention. A great question still elusive is, how and where the distinct pathways involved in the disease overlap and converge to cause the ALS phenotype.

Heterogeneity in the genetic substructure of European populations may be the result of variability in the underlying genetic structure of distinct geographical regions (Novembre et al., 2008). The epidemiology of ALS in Turkey has features representing the pattern seen in other Caucasian populations; however, it has also specific aspects, such as the more complex nature of the disease in molecular and clinical terms: (1) allelic and locus heterogeneity with $>60 \%$ of fALS cases unsolved by conventional methods; (2) interfamilial and intrafamilial phenotypic heterogeneities in large kindreds; (3) variable penetrance rate of mutations; (4) presence of novel mutations; and (5) overall incidence of younger onset. This complexity not only makes ALS research and diagnosis challenging in Turkey, rendering genetic counseling crucial, but also opens many novel opportunities, which can be translated into treatment.

The molecular analysis of ALS and other neurodegenerative disorders in Turkey is expected not only to reveal a complete picture of the distinct genetic background of an admixed population with novel features but also to provide notable insights into essential issues in ALS research that are still outstanding.

\section{Disclosure statement}

The authors declare no conflicts of interest. DNA samples were collected with the approval of the relevant institutional ethic boards, and informed written consent was obtained from each participant.

\section{Acknowledgements}

This study was supported by Suna and İnan Kıraç Foundation (SVIKV) (2005-2008, 2008-2011, 2011-2014), Bogazici University (Grant number 99HB0101 02OB0101 04B101D 08HB102 10B01P8 11B01P6) Research Funds (BAP), and The Scientific and Technological Research Council of Turkey (TUBITAK-SBAG2007 COSTTUBITAK-SBAG2007 TUBITAK-EVRENA-SBAG2009). We gratefully acknowledge their generous contributions. We thank Ilknur Yıldız, Selda Dağdeviren, Irmak Şahbaz, Alireza Khodadadi Jamayran, Helena Alstermark, and Anna Birve for their excellent technical assistance. We extend our thanks to Professor Jeffrey D. Macklis (Harvard Medical School, MA, USA) and Professor Peter Andersen (Umea University, Umea, Sweden) for their constructive contributions to this study; to Professor Coşkun Özdemir and Dr Sevtap Savas for the critical reading of the manuscript; and to Cemile Koçoğlu, Fulya Akçimen, and Hamid Hamzeiy for their assistance in the preparation of the figures and tables. Last but not least, we cordially thank our patients, their families, and the Turkish ALS Association for their invaluable cooperation. This study is dedicated to the memory of our esteemed collaborator Dr Hilmi Özçelik, who passed away on May 2, 2013.

\section{Appendix A. Supplementary data}

Supplementary data associated with this article can be found, in the online version, at http://dx.doi.org/10.1016/j.neurobiolaging. 2014.12.032.

\section{References}

Al-Chalabi, A., Jones, A., Troakes, C., King, A., Al-Sarraj, S., van den Berg, L.H., 2012. The genetics and neuropathology of amyotrophic lateral sclerosis. Acta Neuropathol. 124, 339-352.

Andersen, P.M., Al-Chalabi, A., 2011. Clinical genetics of amyotrophic lateral sclerosis: what do we really know? Nat. Rev. Neurol. 7, 603-615.

Andersen, P.M., Nilsson, P., Ala-Hurula, V., Keranen, M.L., Tarvainen, I., Haltia, T. Nilsson, L., Binzer, M., Forsgren, L., Marklund, S.L., 1995. Amyotrophic lateral sclerosis associated with homozygosity for an Asp90Ala mutation in CuZnsuperoxide dismutase. Nat. Genet. 10, 61-66.

Annesi, G., Savettieri, G., Pugliese, P., D’Amelio, M., Tarantino, P., Ragonese, P., La Bella, V., Piccoli, T., Civitelli, D., Annesi, F., Fierro, B., Piccoli, F., Arabia, G., Caracciolo, M., Ciro Candiano, I.C., Quattrone, A., 2005. DJ-1 mutations and parkinsonism-dementiaamyotrophic lateral sclerosis complex. Ann. Neurol. 58, 803-807.

Battistini, S., Giannini, F., Greco, G., Bibbo, G., Ferrera, L., Marini, V., Causarano, R., Casula, M., Lando, G., Patrosso, M.C., Caponnetto, C., Origone, P., Marocchi, A. Del Corona, A., Siciliano, G., Carrera, P., Mascia, V., Giagheddu, M., Carcassi, C. Orru, S., Garre, C., Penco, S., 2005. SOD1 mutations in amyotrophic lateral sclerosis. Results from a multicenter Italian study. J. Neurol. 252, 782-788.

Belzil, V.V., Daoud, H., St-Onge, J., Desjarlais, A., Bouchard, J.P., Dupre, N., Lacomblez, L., Salachas, F., Pradat, P.F., Meininger, V., Camu, W., Dion, P.A Rouleau, G.A., 2011. Identification of novel FUS mutations in sporadic cases of amyotrophic lateral sclerosis. Amyotroph. Lateral Scler. 12, 113-117.

Brooks, B.R., Miller, R.G., Swash, M., Munsat, T.L., 2000. El Escorial revisited: revised criteria for the diagnosis of amyotrophic lateral sclerosis. Amyotroph. Lateral Scler. Other Motor Neuron Disord. 1, 293-299.

Calvo, A., Moglia, C., Canosa, A., Brunetti, M., Barberis, M., Traynor, B.J., Carrara, G., Valentini, C., Restagno, G., Chio, A., 2014. A de novo nonsense mutation of the FUS gene in an apparently familial amyotrophic lateral sclerosis case. Neurobiol. Aging 35, 1513.e7-1513.e11.

Chio, A., Restagno, G., Brunetti, M., Ossola, I., Calvo, A., Mora, G., Sabatelli, M. Monsurro, M.R., Battistini, S., Mandrioli, J., Salvi, F., Spataro, R., Schymick, J., Traynor, B.J., La Bella, V., 2009. Two Italian kindreds with familial amyotrophic lateral sclerosis due to FUS mutation. Neurobiol. Aging 30, 1272-1275.

Daoud, H., Zhou, S., Noreau, A., Sabbagh, M., Belzil, V., Dionne-Laporte, A. Tranchant, C., Dion, P., Rouleau, G.A., 2012. Exome sequencing reveals SPG11 mutations causing juvenile ALS. Neurobiol. Aging 33, 839.e5-839.e9.

DeJesus-Hernandez, M., Mackenzie, I.R., Boeve, B.F. Boxer, A.L., Baker, M. Rutherford, N.J., Nicholson, A.M., Finch, N.A., Flynn, H., Adamson, J., Kouri, N., Wojtas, A., Sengdy, P., Hsiung, G.Y., Karydas, A., Seeley, W.W., Josephs, K.A. Coppola, G., Geschwind, D.H., Wszolek, Z.K., Feldman, H., Knopman, D.S. Petersen, R.C., Miller, B.L., Dickson, D.W., Boylan, K.B., Graff-Radford, N.R. Rademakers, R., 2011. Expanded GGGGCC hexanucleotide repeat in noncoding region of C9ORF72 causes chromosome 9p-linked FTD and ALS. Neuron 72 $245-256$.

Deng, H.X., Chen, W., Hong, S.T., Boycott, K.M., Gorrie, G.H., Siddique, N., Yang, Y. Fecto, F., Shi, Y., Zhai, H., Jiang, H., Hirano, M., Rampersaud, E., Jansen, G.H., Donkervoort, S., Bigio, E.H., Brooks, B.R., Ajroud, K., Sufit, R.L., Haines, J.L. Mugnaini, E., Pericak-Vance, M.A., Siddique, T., 2011. Mutations in UBQLN2 cause dominant X-linked juvenile and adult-onset ALS and ALS/dementia. Nature $477,211-215$.

Deng, H.X., Hentati, A., Tainer, J.A., Iqbal, Z., Cayabyab, A., Hung, W.Y., Getzoff, E.D. Hu, P., Herzfeldt, B., Roos, R.P, Warner, C., Deng, G., Soriano, E., Smyth, C., Parge, H.E., Ahmed, A., Roses, A.D., Hallewell, R.A., Pericak-Vance, M.A. Siddique, T., 1993. Amyotrophic lateral sclerosis and structural defects in $\mathrm{Cu}, \mathrm{Zn}$ superoxide dismutase. Science 261, 1047-1051.

Dillen, L., Van Langenhove, T., Engelborghs, S., Vandenbulcke, M., Sarafov, S. Tournev, I., Merlin, C., Cras, P., Vandenberghe, R., De Deyn, P.P., Jordanova, A. Cruts, M., Van Broeckhoven, C., van der Zee, J., 2013. Explorative genetic study of UBQLN2 and PFN1 in an extended Flanders-Belgian cohort of frontotemporal lobar degeneration patients. Neurobiol. Aging 34, 1711.e1-1711.e5.

Fecto, F. Yan, J., Vemula, S.P., Liu, E., Yang, Y., Chen, W., Zheng, J.G., Shi, Y, Siddique, N., Arrat, H., Donkervoort, S., Ajroud-Driss, S., Sufit, R.L., Heller, S.L. Deng, H.X., Siddique, T., 2011. SQSTM1 mutations in familial and sporadic amyotrophic lateral sclerosis. Arch. Neurol. 68, 1440-1446.

Ferraiuolo, L., Kirby, J., Grierson, A.J., Sendtner, M., Shaw, P.J., 2011. Molecular pathways of motor neuron injury in amyotrophic lateral sclerosis. Nat. Rev. Neurol. 7, 616-630.

Gamez, J., Corbera-Bellalta, M., Nogales, G., Raguer, N., Garcia-Arumi, E., BadiaCanto, M., Llado-Carbo, E., Alvarez-Sabin, J., 2006. Mutational analysis of the $\mathrm{Cu} /$ Zn superoxide dismutase gene in a Catalan ALS population: should all sporadic ALS cases also be screened for SOD1? J. Neurol. Sci. 247, 21-28.

Gellera, C., Tiloca, C., Del Bo, R., Corrado, L., Pensato, V., Agostini, J., Cereda, C., Ratti, A., Castellotti, B., Corti, S., Bagarotti, A., Cagnin, A., Milani, P., Gabelli, C., Riboldi, G., Mazzini, L., Soraru, G., D’Alfonso, S., Taroni, F., Comi, G.P., Ticozzi, N., 
Silani, V., SLAGEN Consortium, 2013. Ubiquilin 2 mutations in Italian patients with amyotrophic lateral sclerosis and frontotemporal dementia. J. Neurol, Neurosurg. Psychiatry 84, 183-187.

Gitcho, M.A., Baloh, R.H., Chakraverty, S., Mayo, K., Norton, J.B., Levitch, D., Hatanpaa, K.J., White 3rd, C.L., Bigio, E.H., Caselli, R., Baker, M., Al-Lozi, M.T., Morris, J.C., Pestronk, A., Rademakers, R., Goate, A.M., Cairns, N.J., 2008. TDP43 A315T mutation in familial motor neuron disease. Ann. Neurol. 63, $535-538$.

Hadano, S., Hand, C.K., Osuga, H., Yanagisawa, Y., Otomo, A., Devon, R.S., Miyamoto, N., Showguchi-Miyata, J., Okada, Y., Singaraja, R., Figlewicz, D.A., Kwiatkowski, T., Hosler, B.A., Sagie, T., Skaug, J., Nasir, J., Brown Jr., R.H., Scherer, S.W., Rouleau, G.A., Hayden, M.R., Ikeda, J.E., 2001. A gene encoding a putative GTPase regulator is mutated in familial amyotrophic lateral sclerosis 2 . Nat. Genet. 29, 166-173.

Hanby, M.F., Scott, K.M., Scotton, W., Wijesekera, L., Mole, T., Ellis, C.E., Leigh, P.N., Shaw, C.E., Al-Chalabi, A., 2011. The risk to relatives of patients with sporadic amyotrophic lateral sclerosis. Brain 134, 3454-3457.

Hayward, C., Brock, D.J., Minns, R.A., Swingler, R.J., 1998. Homozygosity for Asn86Ser mutation in the CuZn-superoxide dismutase gene produces a severe clinical phenotype in a juvenile onset case of familial amyotrophic lateral sclerosis. J. Med. Genet. 35, 174.

Hermosura, M.C., Nayakanti, H., Dorovkov, M.V., Calderon, F.R., Ryazanov, A.G., Haymer, D.S., Garruto, R.M., 2005. A TRPM7 variant shows altered sensitivity to magnesium that may contribute to the pathogenesis of two Guamanian neurodegenerative disorders. Proc. Natl. Acad. Sci. U. S. A. 102, 11510-11515.

Lattante, S., Rouleau, G.A., Kabashi, E., 2013. TARDBP and FUS mutations associated with amyotrophic lateral sclerosis: summary and update. Hum. Mutat. 34, $812-826$.

Majounie, E., Renton, A.E., Mok, K., Dopper, E.G., Waite, A., Rollinson, S., Chio, A., Restagno, G., Nicolaou, N., Simon-Sanchez, J., van Swieten, J.C., Abramzon, Y., Johnson, J.O., Sendtner, M., Pamphlett, R., Orrell, R.W., Mead, S., Sidle, K.C., Houlden, H., Rohrer, J.D., Morrison, K.E., Pall, H., Talbot, K., Ansorge, O., Hernandez, D.G., Arepalli, S., Sabatelli, M., Mora, G., Corbo, M., Giannini, F., Calvo, A., Englund, E., Borghero, G., Floris, G.L., Remes, A.M., Laaksovirta, H., McCluskey, L., Trojanowski, J.Q., Van Deerlin, V.M., Schellenberg, G.D., Nalls, M.A., Drory, V.E., Lu, C.S., Yeh, T.H., Ishiura, H., Takahashi, Y., Tsuji, S., Le Ber, I., Brice, A., Drepper, C., Williams, N., Kirby, J., Shaw, P., Hardy, J., Tienari, P.J., Heutink, P., Morris, H.R., Pickering-Brown, S., Traynor, B.J., 2012. Frequency of the C9orf72 hexanucleotide repeat expansion in patients with amyotrophic lateral sclerosis and frontotemporal dementia: a cross-sectional study. Lancet Neurol. 11, 323-330.

Maystadt, I., Rezsohazy, R., Barkats, M., Duque, S., Vannuffel, P., Remacle, S., Lambert, B., Najimi, M., Sokal, E., Munnich, A., Viollet, L., Verellen-Dumoulin, C., 2007. The nuclear factor kappaB-activator gene PLEKHG5 is mutated in a form of autosomal recessive lower motor neuron disease with childhood onset. Am. J. Hum. Genet. 81, 67-76.

Millecamps, S., Corcia, P., Cazeneuve, C., Boillee, S., Seilhean, D., Danel-Brunaud, V., Vandenberghe, N., Pradat, P.F., Le Forestier, N., Lacomblez, L., Bruneteau, G., Camu, W., Brice, A., Meininger, V., LeGuern, E., Salachas, F., 2012. Mutations in UBQLN2 are rare in French amyotrophic lateral sclerosis. Neurobiol. Aging 33, 839.e1-839.e3.

Nakanishi, T., Kishikawa, M., Miyazaki, A., Shimizu, A., Ogawa, Y., Sakoda, S., Ohi, T., Shoji, H., 1998. Simple and defined method to detect the SOD-1 mutants from patients with familial amyotrophic lateral sclerosis by mass spectrometry J. Neurosci. Methods 81, 41-44.

Novembre, J., Johnson, T., Bryc, K., Kutalik, Z., Boyko, A.R., Auton, A., Indap, A. King, K.S., Bergmann, S., Nelson, M.R., Stephens, M., Bustamante, C.D., 2008. Genes mirror geography within Europe. Nature 456, 98-101.

Orlacchio, A., Babalini, C., Borreca, A., Patrono, C., Massa, R., Basaran, S., Munhoz, R.P. Rogaeva, E.A., St George-Hyslop, P.H., Bernardi, G., Kawarai, T., 2010. SPATACSIN mutations cause autosomal recessive juvenile amyotrophic lateral sclerosis. Brain 133, 591-598.

Pasinelli, P., Brown, R.H., 2006. Molecular biology of amyotrophic lateral sclerosis: insights from genetics. Nat. Rev. Neurosci. 7, 710-723.

Pfister, T., Sekhon, R., White, M., Scott, P., Munro, S., Johnston, M., Kalra, S. Korngut, L., 2013. Familial amyotrophic lateral sclerosis in Alberta, Canada. Amyotroph. Lateral Scler. Frontotemporal Degener. 14, 273-277.

Rabe, M., Felbecker, A., Waibel, S., Steinbach, P., Winter, P., Muller, U., Ludolph, A.C. 2010. The epidemiology of CuZn-SOD mutations in Germany: a study of 217 families. J. Neurol. 257, 1298-1302.

Renton, A.E., Majounie, E., Waite, A., Simon-Sanchez, J., Rollinson, S., Gibbs, J.R. Schymick, J.C., Laaksovirta, H., van Swieten, J.C., Myllykangas, L., Kalimo, H. Paetau, A., Abramzon, Y., Remes, A.M., Kaganovich, A., Scholz, S.W. Duckworth, J., Ding, J., Harmer, D.W., Hernandez, D.G., Johnson, J.O., Mok, K., Ryten, M., Trabzuni, D., Guerreiro, R.J., Orrell, R.W., Neal, J., Murray, A. Pearson, J., Jansen, I.E., Sondervan, D., Seelaar, H., Blake, D., Young, K., Halliwell, N., Callister, J.B., Toulson, G., Richardson, A., Gerhard, A., Snowden, J. Mann, D., Neary, D., Nalls, M.A., Peuralinna, T., Jansson, L., Isoviita, V.M., Kaivorinne, A.L., Holtta-Vuori, M., Ikonen, E., Sulkava, R., Benatar, M., Wuu, J., Chio, A., Restagno, G., Borghero, G., Sabatelli, M., Heckerman, D., Rogaeva, E. Zinman, L., Rothstein, J.D., Sendtner, M., Drepper, C., Eichler, E.E., Alkan, C. Abdullaev, Z., Pack, S.D., Dutra, A., Pak, E., Hardy, J., Singleton, A., Williams, N.M., Heutink, P., Pickering-Brown, S., Morris, H.R., Tienari, P.J., Traynor, B.J., 2011 A hexanucleotide repeat expansion in C9ORF72 is the cause of chromosome 9p21-linked ALS-FTD. Neuron 72, 257-268.

Rutherford, N.J., Zhang, Y.J., Baker, M., Gass, J.M., Finch, N.A., Xu, Y.F., Stewart, H. Kelley, B.J., Kuntz, K., Crook, R.J., Sreedharan, J., Vance, C., Sorenson, E., Lippa, C., Bigio, E.H., Geschwind, D.H., Knopman, D.S., Mitsumoto, H., Petersen, R.C. Cashman, N.R., Hutton, M., Shaw, C.E., Boylan, K.B., Boeve, B., Graff-Radford, N.R., Wszolek, Z.K., Caselli, R.J., Dickson, D.W., Mackenzie, I.R., Petrucelli, L., Rademakers, R., 2008. Novel mutations in TARDBP (TDP-43) in patients with familial amyotrophic lateral sclerosis. PLoS Genet. 4, e1000193.

Ticozzi, N., Tiloca, C., Morelli, C., Colombrita, C., Poletti, B., Doretti, A., Maderna, L. Messina, S., Ratti, A., Silani, V., 2011. Genetics of familial amyotrophic lateral sclerosis. Arch. Ital. Biol. 149, 65-82.

van Doormaal, P.T., van Rheenen, W., van Blitterswijk, M., Schellevis, R.D. Schelhaas, H.J., de Visser, M., van der Kooi, A.J., Veldink, J.H., van den Berg, L.H., 2012. UBQLN2 in familial amyotrophic lateral sclerosis in The Netherlands. Neurobiol. Aging 33, 2233.e7-2233.e8.

Vengoechea, J., David, M.P., Yaghi, S.R., Carpenter, L., Rudnicki, S.A., 2013. Clinica variability and female penetrance in X-linked familial FTD/ALS caused by a P506S mutation in UBQLN2. Amyotroph. Lateral Scler. Frontotemporal Degener. 14, 615-619.

Williams, K.L., Warraich, S.T., Yang, S., Solski, J.A., Fernando, R., Rouleau, G.A., Nicholson, G.A., Blair, I.P., 2012. UBQLN2/ubiquilin 2 mutation and pathology in familial amyotrophic lateral sclerosis. Neurobiol. Aging 33, 2527.e3-2527.e10. 